\title{
Nutrient Elasticities in a Complete Food Demand System
}

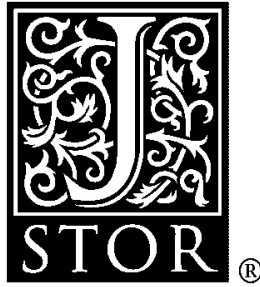

\author{
Kuo S. Huang
}

American Journal of Agricultural Economics, Vol. 78, No. 1. (Feb., 1996), pp. 21-29.

Stable URL:

http://links.jstor.org/sici?sici=0002-9092\%28199602\%2978\%3A1\%3C21\%3ANEIACF\%3E2.0.CO\%3B2-2

American Journal of Agricultural Economics is currently published by American Agricultural Economics Association.

Your use of the JSTOR archive indicates your acceptance of JSTOR's Terms and Conditions of Use, available at

http://www.jstor.org/about/terms.html. JSTOR's Terms and Conditions of Use provides, in part, that unless you have obtained prior permission, you may not download an entire issue of a journal or multiple copies of articles, and you may use content in the JSTOR archive only for your personal, non-commercial use.

Please contact the publisher regarding any further use of this work. Publisher contact information may be obtained at http://www.jstor.org/journals/aaea.html.

Each copy of any part of a JSTOR transmission must contain the same copyright notice that appears on the screen or printed page of such transmission.

The JSTOR Archive is a trusted digital repository providing for long-term preservation and access to leading academic journals and scholarly literature from around the world. The Archive is supported by libraries, scholarly societies, publishers, and foundations. It is an initiative of JSTOR, a not-for-profit organization with a mission to help the scholarly community take advantage of advances in technology. For more information regarding JSTOR, please contact support@ jstor.org. 


\title{
Nutrient Elasticities in a Complete Food Demand System
}

\author{
Kuo S. Huang
}

This study explores the linkage of the determinants of food choice with consumer nutrient availability by developing a procedure to measure changes in nutrient availability as the demand for food items change. It uses demand elasticities from traditional demand analysis to estimate elasticities of changes in the nutritional content of consumer diets. The procedure is applied to estimate nutrient elasticities for fifteen nutrients in response to changes in thirty-five food prices and per capita income.

Key words: complete food demand system, nutrient elasticities.

The issues of health and diet have become a major concern for consumers. Medical evidence links excessive saturated fat and cholesterol in the typical American's diet with heart diseasethe leading cause of death in the United States. Also, some women and children in low-income households may have nutritional deficiencies and nutrition-related health problems (Senauer, Asp, and Kinsey, p. 222). In 1990, the U.S. National Nutrition Monitoring and Related Research Act was passed. This act calls for a tenyear comprehensive plan to provide information about the role and status of nutrition factors that contribute to the health of Americans. An interagency board, consisting of representatives from twenty-two federal agencies, coordinates the nutrition monitoring and related research activities.

Given the demand structure for food and the bundle of nutrient attributes each food product contains, it is possible to derive the implied relationship between nutrient availability and changes in food prices and income. Only a few studies have incorporated nutritional factors into food demand analyses. Some use a cholesterol information index by measuring the number of medical journal articles that disseminate cholesterol information as a variable in demand

Kuo S. Huang is an agricultural economist with the Economic Research Service, U.S. Department of Agriculture.

The author thanks James Blaylock and $A J A E$ reviewers for helpful comments. The views are the author's and do not necessarily represent those of the Economic Research Service or the U.S. Department of Agriculture. equations (Brown and Schrader, Capps and Schmitz). Some fit demand equations for specific nutrients as functions of income and sociodemographic variables from household survey data (Adrian and Daniel, Devaney and Fraker, Basiotis et al.). Others propose a formula to calculate nutrient elasticities for use in measuring price and income effects on nutrient availability, but provide no information on how to derive the formula from an underlying demand model (Pitt; Sahn; Gould, Cox, and Perali).

Lancaster provides a conceptual framework to link food choice and nutritional status. He views nutrients as attributes or characteristics of food consumption, and consumers attain the nutrient attributes they most desire by maximizing utility as a function of nutrient attributes, as opposed to food quantities in classical demand theory. The consumer choice problem is to maximize the utility function subject to budget constraint and a set of transformation equations that link nutrient availability to food consumption. This approach, however, is rather difficult to implement empirically because a nonlinear programming problem has to be solved to obtain the nutritional implication of food consumption.

A comprehensive framework for studying the effects of economic factors on nutritional status of consumers is not available. The purpose of this study is to link food choice with nutritional status in the context of the classical demand framework. Instead of applying Lancaster's programming approach, this study develops an 
efficient procedure to measure nutrient availability by way of demand elasticities for food items from a traditional demand analysis. In particular, interdependent demand relationships including own- and cross-price and income effects of a complete food demand system are incorporated directly into the measurement of nutrient elasticities. This procedure is applied to a demand system consisting of thirty-five food categories to estimate nutrient elasticities for fifteen nutrients. These results provide useful information for nutrition monitoring and related research activities.

\section{Conceptual Framework}

To measure nutrient elasticities, this study applies the following differential-form demand model extensively used by Huang. Let $p_{i}$ and $q_{i}$ denote the $i$ th price and associated quantity demanded in the allocation of a representative consumer's income $m$ across a set of $n$ commodities including foods and nonfoods. The demand relationships can be approximated by relating small changes from any given point on the $n$-commodity demand surface as

$$
d q_{i}=\sum_{j}\left(\partial q_{i} / \partial p_{j}\right) d p_{j}+\left(\partial q_{i} / \partial m\right) d m
$$

All subscripts of variables and summation throughout this paper refer to $n$ commodities and $\ell$ nutrients as $i, j=1,2, \ldots, n$ and $k=1,2, \ldots, \ell$.

By further expressing the price and income slopes in terms of elasticities, a differentialform demand model can be obtained as

$$
d q_{i} / q_{i}=\sum_{j} e_{i j}\left(d p_{j} / p_{j}\right)+\eta_{i}(d m / m)
$$

where $e_{i j}=\left(\partial q_{i} / \partial p_{j}\right)\left(p_{j} / q_{i}\right)$ and $\eta_{i}=\left(\partial q_{i} / \partial m\right)(m /$ $\left.q_{i}\right)$ are, respectively, price and income elasticities. This demand model is a general approximation of conceptual demand relationships. In view of classical demand theory, the elasticities are constrained by symmetry $\left(e_{j i} / w_{i}+\eta_{j}=e_{i j} / w_{j}\right.$ $\left.+\eta_{i}\right)$, homogeneity $\left(\sum_{j} e_{i j}+\eta_{i}=0\right)$, and Engel aggregation $\left(\sum_{i} w_{i} \eta_{i}=1\right)$, where $w_{i}=p_{i} q_{i} / m$ is the $i$ th expenditure share. The fixed parameters in the model representing demand elasticities may be too strong an assumption, because restrictions are thereby placed on the implied utility structure. Nevertheless, as shown below, the advantage of using this demand model is that the estimated demand elasticities can be applied directly to the measurement of nutrient elasticities.
To explore the linkage of the demand model to nutrient availability, information about the nutrient values of each food consumed is needed. Let $a_{k i}$ be the amount of the $k$ th nutrient obtained from a unit of the $i$ th food. The total amount of that nutrient obtained from various foods, say $\phi_{k}$, may be expressed as

$$
\phi_{k}=\sum_{i} a_{k i} q_{i}
$$

This is what Lancaster called the "consumption technology" of consumer behavior. The values of $a_{k i}$ 's for nonfoods will be assigned to zero; thus the terms associated with nonfoods will disappear. This equation, including all foods consumed, plays a central role in the transformation of food demands into nutrient availability.

By substituting the demand equation (1) for the quantity variable of equation (3), changes in consumer nutrient availability become

$$
d \phi_{k}=\sum_{i} a_{k i}\left[\sum_{j}\left(\partial q_{i} / \partial p_{j}\right) d p_{j}+\left(\partial q_{i} / \partial m\right) d m\right] .
$$

Furthermore, the relative changes of consumer nutrient availability can be expressed as functions of the relative changes in food prices and per capita income as follows:

$$
\begin{aligned}
d \phi_{k} / \phi_{k} & =\sum_{j}\left(\sum_{i} e_{i j} a_{k i} q_{i} / \phi_{k}\right) d p_{j} / p_{j} \\
& +\left(\sum_{i} \eta_{i} a_{k i} q_{i} / \phi_{k}\right) d m / m \\
& =\sum_{j} \pi_{k j} d p_{j} / p_{j}+\rho_{k} d m / m
\end{aligned}
$$

where $\pi_{k j}=\sum_{i} e_{i j} a_{k i} q_{i} / \phi_{k}$ is a price elasticity measure relating the effect of the $j$ th food price on the availability of the $k$ th nutrient, and $\rho_{k}=$ $\sum_{i} \eta_{i} a_{k i} q_{i} / \phi_{k}$ is an income elasticity measure relating the effect of income on the availability of that nutrient.

Obviously, the measurement of $\pi_{k j}$ represents the weighted average of all own- and crossprice elasticities $\left(e_{i j}\right.$ 's) in response to the $j$ th price with each weight expressed as the share of each food's contribution to the $k$ th nutrient $\left(a_{k i} q_{i} / \phi_{k}\right.$ 's). Similarly, the measurement of $\rho_{k}$ represents the weighted average of all income elasticities $\left(\eta_{i}\right.$ 's) with each weight again expressed as the share of each food's contribution to the $k$ th nutrient. Thus the general calculation of nutrient elasticity matrix, say $\mathbf{N}$, for the case of $\ell$ nutrients and $n$ foods can be obtained as a product of multiplying matrix $\mathbf{S}$ by matrix $\mathbf{D}$ as follows:

$$
\mathbf{N}=\mathbf{S} * \mathbf{D}
$$

where $\mathbf{N}$ is the $\ell \times(n+1)$ matrix of nutrient 
elasticities in response to changes of food prices and income, $\mathbf{S}$ is the $\ell \times n$ matrix with entries of each row indicating a food's share of a particular nutrient, and $\mathbf{D}$ is the $n \times(n+1)$ matrix of demand elasticities. From these nutrient elasticity measurements, a change in a particular food price or per capita income will affect all food quantities demanded through the interdependent demand relationships and thus cause the levels of consumer nutrient availability to change simultaneously.

\section{Empirical Application}

The procedure for measuring nutrient elasticities is applied to the U.S. food sector for a total nutrient profile of consumer diets. A total of thirty-five food categories are covered. In addition to food demand elasticities, information about the nutrition attributes of foods and the amount of per capita food consumption are required for calculating nutrient elasticities. Most nutritive values of foods are compiled from Gebhardt and Matthews's Nutritive Value of Foods, which gives a detailed account of nutritive values for household measures of commonly used foods. The nutrition attributes of beef, pork, chicken, and turkey are obtained from the U.S. Department of Agriculture (USDA), Agricultural Handbooks Nos. 8-5, 810 , and $8-13$. These handbooks provide additional nutritive values of meat carcasses, which contain more adequate nutrition information for the U.S. disappearance data for meat quantities used in this study.

The nutrition values of food per pound for fifteen selected nutrients are compiled in table 1. Food energy is measured in food calories (kcal); protein, fat, and carbohydrate in grams; vitamin $A$ in retinol equivalent (re); and all other nutrients in milligrams. Each food category of cheese, flour, rice, fats and oils, peanuts and nuts, and sugar provides relatively higher food energy (above $1,500 \mathrm{kcal}$ ) than other foods. These food energy contents are closely related to three energy-yielding nutrients: protein, fat, and carbohydrate. Cheese, peanuts, and nuts have high levels of protein and fat. Butter, margarine, and cooking oils are mostly fats, while flour, rice, and sugar are mainly carbohydrates. The cholesterol levels are highest for eggs $(1,932 \mathrm{mg})$ and butter $(991$ $\mathrm{mg}$ ). Carrots are exceptionally rich in vitamin A $(12,758$ re $)$. Fruits and vegetables are a major source of vitamin C, especially oranges (242.4 $\mathrm{mg}$ ) and grapefruits $(155 \mathrm{mg})$.
In addition to the unit nutritive value of food, the amount of food consumed is another factor determining the level of nutrients available to consumers. Averages of food consumptions over 1989-93 (listed in the last column of table 1) are compiled from Putnam and Allshouse's Food Consumption, Prices, and Expenditures. The consumption of chicken $(73.4 \mathrm{lb})$ is more than beef $(68 \mathrm{lb})$ and pork $(51 \mathrm{lb})$. Staple foods such as milk $(220 \mathrm{lb})$ and flour $(150 \mathrm{lb})$ are consumed heavily. By multiplying the amount of each food consumption by its unit nutritive values, total nutrients available to consumers and food shares of nutrients are obtained, as presented in table 2 . This set of nutrient information depicts the source of nutrients and provides a basis [the $\mathbf{S}$ matrix in equation (6)] for measuring nutrient elasticities.

In table 2, combined flour and rice consumption is a major source of energy $(24.97 \%)$, protein $(19.77 \%)$, carbohydrate $(48.85 \%)$, phosphorus $(11.88 \%)$, iron $(57.86 \%)$, thiamin $(57.66 \%)$, riboflavin $(29.92 \%)$, and niacin $(43.87 \%)$. The significant nutrients in flour and rice are consistent with USDA's suggested daily food choices in The Food Guide Pyramid-six to eleven servings of bread, cereals, rice, and pasta, and two to five servings for each of the other four food groups: $(a)$ vegetables; $(b)$ fruits; $(c)$ meat, poultry, fish, dry beans, eggs, and nuts; and $(d)$ milk, yogurt, and cheese. Other major sources of protein are beef $(13.02 \%)$, pork $(7.99 \%)$, chicken $(12.74 \%)$, and milk $(9.89 \%)$. As expected, the consumption of eggs gives the highest level of cholesterol by $38 \%$, while beef, pork, and chicken each contribute about $10 \%$ of cholesterol. Cheese, milk, and evaporated and dry milk are major sources of calcium, phosphorus, potassium, sodium, and vitamin A. Carrots provide about $23 \%$ of vitamin $\mathrm{A}$. Oranges and orange juice, are the major source of vitamin $\mathrm{C}$, providing $11 \%$ and $34 \%$, respectively.

Food demand elasticities are another important component [the D matrix in equation (6)] in computing nutrient elasticities. For purposes of this study, a portion of the complete food demand system reported in Huang is used. Some minor "other" food categories and a nonfood sector in Huang's demand system are excluded from nutritional analysis because of either difficulty or irrelevance in defining nutritive value. Huang's demand system was specified as in equation (2) and estimated using annual data from 1953 to 1990 . Constrained maximum likelihood is used for demand system estimation, with the parametric constraints of homogeneity, 


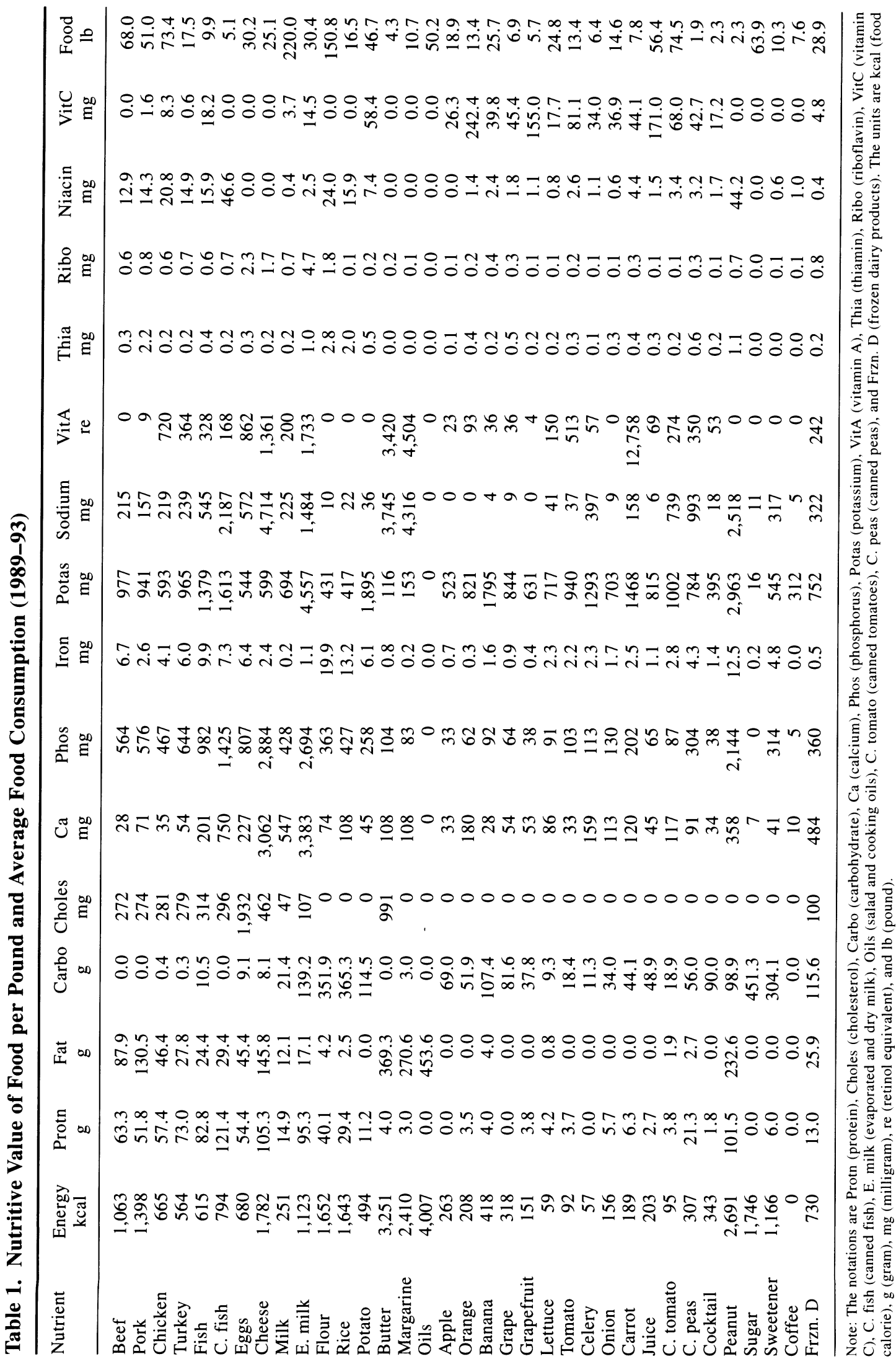


Table 2. Food Share of Nutrient Based on Average Food Consumption (1989-93)

\begin{tabular}{|c|c|c|c|c|c|c|c|c|c|c|c|c|c|c|c|}
\hline Nutrient & Energy & Protn & Fat & Carbo & Choles & $\mathrm{Ca}$ & Phos & Iron & Potas & Sodium & VitA & Thia & Ribo & Niacin & VitC \\
\hline & \multicolumn{15}{|c|}{ Percentage } \\
\hline Beef & 6.53 & 13.02 & 10.94 & 0.00 & 12.05 & 0.51 & 7.37 & 8.17 & 6.78 & 3.34 & 0.00 & 2.39 & 4.44 & 9.93 & 0.00 \\
\hline Pork & 6.45 & 7.99 & 12.20 & 0.00 & 9.12 & 0.96 & 5.65 & 2.36 & 4.91 & 1.83 & 0.11 & 14.21 & 4.28 & 8.25 & 0.29 \\
\hline Chicken & 4.41 & 12.74 & 6.24 & 0.02 & 13.45 & 0.68 & 6.59 & 5.40 & 4.45 & 3.67 & 12.30 & 1.76 & 4.66 & 17.22 & 2.14 \\
\hline Turkey & 0.89 & 3.87 & 0.89 & 0.00 & 3.19 & 0.25 & 2.17 & 1.90 & 1.73 & 0.96 & 1.49 & 0.51 & 1.39 & 2.94 & 0.04 \\
\hline Fish & 0.55 & 2.48 & 0.44 & 0.09 & 2.03 & 0.53 & 1.87 & 1.76 & 1.40 & 1.23 & 0.76 & 0.50 & 0.60 & 1.78 & 0.64 \\
\hline C. fish & 0.37 & 1.89 & 0.28 & 0.00 & 0.99 & 1.02 & 1.41 & 0.68 & 0.85 & 2.57 & 0.20 & 0.11 & 0.38 & 2.70 & 0.00 \\
\hline Eggs & 1.85 & 4.97 & 2.51 & 0.23 & 38.00 & 1.82 & 4.68 & 3.44 & 1.68 & 3.94 & 6.05 & 1.03 & 7.45 & 0.00 & 0.00 \\
\hline Cheese & 4.05 & 8.01 & 6.71 & 0.17 & 7.57 & 20.45 & 13.94 & 1.10 & 1.54 & 27.06 & 7.96 & 0.51 & 4.66 & 0.00 & 0.00 \\
\hline Milk & 4.99 & 9.89 & 4.87 & 3.89 & 6.80 & 31.94 & 18.08 & 0.73 & 15.59 & 11.30 & 10.23 & 4.89 & 17.82 & 0.92 & 2.88 \\
\hline E. milk & 3.09 & 8.77 & 0.95 & 3.50 & 2.11 & 27.34 & 15.75 & 0.61 & 14.15 & 10.31 & 12.27 & 3.99 & 15.54 & 0.84 & 1.55 \\
\hline Flour & 22.52 & 18.30 & 1.15 & 43.86 & 0.00 & 2.97 & 10.53 & 53.93 & 6.64 & 0.35 & 0.00 & 53.53 & 29.66 & 40.90 & 0.00 \\
\hline Rice & 2.45 & 1.47 & 0.07 & 4.99 & 0.00 & 0.47 & 1.35 & 3.93 & 0.70 & 0.08 & 0.00 & 4.13 & 0.26 & 2.97 & 0.00 \\
\hline Potato & 2.08 & 1.59 & 0.00 & 4.42 & 0.00 & 0.56 & 2.32 & 5.09 & 9.03 & 0.38 & 0.00 & 2.90 & 0.80 & 3.90 & 9.59 \\
\hline Butter & 1.28 & 0.05 & 2.93 & 0.00 & 2.81 & 0.12 & 0.09 & 0.06 & 0.05 & 3.71 & 3.45 & 0.02 & 0.08 & 0.00 & 0.00 \\
\hline Margarine & 2.33 & 0.10 & 5.30 & 0.03 & 0.00 & 0.31 & 0.17 & 0.04 & 0.17 & 10.54 & 11.22 & 0.04 & 0.15 & 0.00 & 0.00 \\
\hline Oils & 18.16 & 0.00 & 41.66 & 0.00 & 0.00 & 0.00 & 0.00 & 0.00 & 0.00 & 0.00 & 0.00 & 0.00 & 0.00 & 0.00 & 0.00 \\
\hline Apple & 0.45 & 0.00 & 0.00 & 1.08 & 0.00 & 0.17 & 0.12 & 0.22 & 1.01 & 0.00 & 0.10 & 0.16 & 0.14 & 0.01 & 1.75 \\
\hline Orange & 0.25 & 0.14 & 0.00 & 0.57 & 0.00 & 0.64 & 0.16 & 0.08 & 1.12 & 0.00 & 0.29 & 0.64 & 0.25 & 0.21 & 11.41 \\
\hline Banana & 0.97 & 0.31 & 0.19 & 2.28 & 0.00 & 0.19 & 0.45 & 0.73 & 4.70 & 0.02 & 0.21 & 0.64 & 1.22 & 0.69 & 3.59 \\
\hline Grape & 0.20 & 0.00 & 0.00 & 0.46 & 0.00 & 0.10 & 0.08 & 0.11 & 0.59 & 0.01 & 0.06 & 0.39 & 0.20 & 0.14 & 1.10 \\
\hline Grapefruit & 0.08 & 0.07 & 0.00 & 0.18 & 0.00 & 0.08 & 0.04 & 0.04 & 0.37 & 0.00 & 0.01 & 0.11 & 0.05 & 0.07 & 3.11 \\
\hline Lettuce & 0.13 & 0.32 & 0.04 & 0.19 & 0.00 & 0.57 & 0.43 & 1.01 & 1.81 & 0.23 & 0.86 & 0.66 & 0.36 & 0.24 & 1.54 \\
\hline Tomato & 0.11 & 0.15 & 0.00 & 0.20 & 0.00 & 0.12 & 0.27 & 0.53 & 1.29 & 0.11 & 1.60 & 0.44 & 0.32 & 0.39 & 3.83 \\
\hline Celery & 0.03 & 0.00 & 0.00 & 0.06 & 0.00 & 0.27 & 0.14 & 0.26 & 0.84 & 0.58 & 0.08 & 0.09 & 0.08 & 0.08 & 0.77 \\
\hline Onion & 0.21 & 0.25 & 0.00 & 0.41 & 0.00 & 0.44 & 0.37 & 0.44 & 1.05 & 0.03 & 0.00 & 0.52 & 0.09 & 0.09 & 1.89 \\
\hline Carrot & 0.13 & 0.15 & 0.00 & 0.29 & 0.00 & 0.25 & 0.30 & 0.35 & 1.17 & 0.28 & 23.28 & 0.43 & 0.22 & 0.39 & 1.22 \\
\hline Juice & 1.04 & 0.47 & 0.00 & 2.28 & 0.00 & 0.67 & 0.71 & 1.11 & 4.69 & 0.08 & 0.90 & 2.30 & 0.70 & 0.93 & 33.94 \\
\hline C. tomato & 0.64 & 0.85 & 0.26 & 1.16 & 0.00 & 2.32 & 1.24 & 3.79 & 7.62 & 12.56 & 4.75 & 1.95 & 1.07 & 2.86 & 17.83 \\
\hline C. peas & 0.05 & 0.12 & 0.01 & 0.09 & 0.00 & 0.04 & 0.11 & 0.14 & 0.15 & 0.42 & 0.15 & 0.13 & 0.07 & 0.07 & 0.28 \\
\hline Cocktail & 0.07 & 0.01 & 0.00 & 0.17 & 0.00 & 0.02 & 0.02 & 0.06 & 0.09 & 0.01 & 0.03 & 0.05 & 0.03 & 0.04 & 0.14 \\
\hline Peanut & 0.56 & 0.71 & 0.98 & 0.19 & 0.00 & 0.22 & 0.95 & 0.52 & 0.70 & 1.32 & 0.00 & 0.33 & 0.18 & 1.15 & 0.00 \\
\hline Sugar & 10.09 & 0.00 & 0.00 & 23.85 & 0.00 & 0.12 & 0.00 & 0.26 & 0.10 & 0.17 & 0.00 & 0.00 & 0.00 & 0.00 & 0.00 \\
\hline Sweetener & 1.09 & 0.19 & 0.00 & 2.59 & 0.00 & 0.11 & 0.62 & 0.89 & 0.57 & 0.75 & 0.00 & 0.00 & 0.13 & 0.07 & 0.00 \\
\hline Coffee & 0.00 & 0.00 & 0.00 & 0.00 & 0.00 & 0.02 & 0.01 & 0.00 & 0.24 & 0.01 & 0.00 & 0.00 & 0.04 & 0.09 & 0.00 \\
\hline Frzn. D & 1.91 & 1.14 & 1.37 & 2.76 & 1.88 & 3.72 & 2.00 & 0.24 & 2.22 & 2.13 & 1.63 & 0.63 & 2.66 & 0.13 & 0.48 \\
\hline Total & 100 & 100 & 100 & 100 & 100 & 100 & 100 & 100 & 100 & 100 & 100 & 100 & 100 & 100 & 100 \\
\hline
\end{tabular}

Note: The notations are Protn (protein), Choles (cholesterol), Carbo (carbohydrate), Ca (calcium), Phos (phosphorus), Potas (potassium), VitA (vitamin A), Thia (thiamin), Ribo (riboflavin), VitC (vitamin C), C. fish (canned fish), E. milk (evaporated and dry milk), Oils (salad and cooking oils), C. tomato (canned tomatoes), C. peas (canned peas), and Frzn. D (frozen dairy products). 
Table 3. Own-Price and Income Elasticities Used in this Study

\begin{tabular}{|c|c|c|c|c|c|}
\hline $\begin{array}{l}\text { Food } \\
\text { Category }\end{array}$ & \multicolumn{2}{|c|}{$\begin{array}{c}\text { Price } \\
\text { Elasticity }\end{array}$} & \multicolumn{2}{|c|}{$\begin{array}{c}\text { Income } \\
\text { Elasticity }\end{array}$} & $\begin{array}{l}\begin{array}{l}\text { Root-Mean- } \\
\text { Square Error }\end{array} \\
\text { Percentage }\end{array}$ \\
\hline Beef & -0.6212 & $(0.0572)$ & 0.3923 & $(0.1240)$ & 2.77 \\
\hline Pork & -0.7281 & $(0.0424)$ & 0.6593 & $(0.1461)$ & 3.28 \\
\hline Chicken & -0.3723 & $(0.0560)$ & 0.0769 & $(0.1884)$ & 3.88 \\
\hline Turkey & -0.5345 & $(0.1217)$ & -0.1267 & $(0.3449)$ & 6.23 \\
\hline Fish & 0.1212 & $(0.1606)$ & 0.4290 & $(0.3076)$ & 4.50 \\
\hline C. fish & -0.3715 & $(0.1486)$ & 0.3942 & $(0.3621)$ & 4.28 \\
\hline Eggs & -0.1103 & $(0.0172)$ & 0.2865 & $(0.0816)$ & 2.53 \\
\hline Cheese & -0.2472 & $(0.0833)$ & 0.4181 & $(0.1934)$ & 3.75 \\
\hline Milk & -0.0431 & $(0.1259)$ & 0.1193 & $(0.0718)$ & 1.38 \\
\hline E.milk & -0.2764 & $(0.5383)$ & 0.5151 & $(0.2584)$ & 2.61 \\
\hline Flour & -0.0777 & $(0.1037)$ & 0.1314 & $(0.1172)$ & 1.54 \\
\hline Rice & 0.0661 & $(0.1232)$ & 0.1475 & $(0.4537)$ & 7.21 \\
\hline Potato & -0.0983 & $(0.0531)$ & 0.1100 & $(0.3235)$ & 5.34 \\
\hline Butter & -0.2428 & $(0.1613)$ & 0.5386 & $(0.3659)$ & 4.12 \\
\hline Margarine & -0.0087 & $(0.1470)$ & -0.3355 & $(0.2494)$ & 3.05 \\
\hline Oils & -0.1393 & $(0.0650)$ & 0.4938 & $(0.1713)$ & 2.53 \\
\hline Apple & -0.1902 & $(0.1295)$ & -0.3617 & $(0.4206)$ & 7.38 \\
\hline Orange & -0.8486 & $(0.1154)$ & -0.1646 & $(0.4765)$ & 7.34 \\
\hline Banana & -0.4985 & $(0.1337)$ & 0.0940 & $(0.3658)$ & 4.68 \\
\hline Grape & -1.1795 & $(0.1591)$ & 0.5613 & $(0.5710)$ & 7.99 \\
\hline Grapefruit & -0.4546 & $(0.1246)$ & -0.4896 & $(0.5712)$ & 9.06 \\
\hline Lettuce & -0.0904 & $(0.0873)$ & 0.3720 & $(0.2803)$ & 4.46 \\
\hline Tomato & -0.6220 & $(0.0845)$ & 0.9184 & $(0.1906)$ & 3.26 \\
\hline Celery & -0.0775 & $(0.0638)$ & 0.7250 & $(0.2283)$ & 2.85 \\
\hline Onion & -0.2066 & $(0.0474)$ & 0.0783 & $(0.3184)$ & 4.53 \\
\hline Carrot & -0.5339 & $(0.2014)$ & 0.6750 & $(0.5309)$ & 7.15 \\
\hline Juice & -0.5575 & $(0.1081)$ & 0.3664 & $(0.5539)$ & 8.05 \\
\hline C. tomato & -0.1688 & $(0.0885)$ & 0.8684 & $(0.2654)$ & 3.71 \\
\hline C. peas & -0.5335 & $(0.1580)$ & 0.6282 & $(0.3599)$ & 5.16 \\
\hline Cocktail & -0.7400 & $(0.3536)$ & 0.7172 & $(0.5848)$ & 6.03 \\
\hline Peanut & -0.1685 & $(0.0778)$ & 0.0992 & $(0.2551)$ & 3.56 \\
\hline Sugar & -0.0368 & $(0.0220)$ & 0.0059 & $(0.1761)$ & 2.68 \\
\hline Sweetener & -0.0522 & $(0.0938)$ & 0.4190 & $(0.2659)$ & 4.28 \\
\hline Coffee & -0.1761 & $(0.0289)$ & 0.8176 & $(0.2153)$ & 4.02 \\
\hline Frzn. D & -0.0784 & $(0.0955)$ & 0.2534 & $(0.1366)$ & 1.39 \\
\hline
\end{tabular}

Note: Compiled from Huang. The figures in parentheses are the standard errors of estimates. The notations are C. fish (canned fish), E milk (evaporated and dry milk), Oils (salad and cooking oils), C. tomato (canned tomatoes), C. peas (canned peas), and Frzn. D (frozen dairy products)

symmetry, and Engel aggregation imposed at sample means. The food quantity data are compiled from Food Consumption, Prices, and Expenditures. Most food category price indexes are components of the consumer price index obtained from the U.S. Department of Labor. Per capita total expenditure is computed by dividing the personal consumption expenditures (obtained from the U.S. Department of Commerce) by the civilian population of fifty states on July 1 of each year.

The demand elasticities compiled for this study contain 1,260 estimates of own- and cross-price elasticities and income elasticities for thirty-five food categories. Among demand elasticity estimates, for example, the own-price elasticities for major meats are beef $(-0.6212)$, pork $(-0.7281)$, and chicken $(-0.3723)$, and their corresponding income elasticities are beef $(0.3923)$, pork $(0.6593)$, and chicken $(0.0769)$. The cross-price elasticities of beef in response to the price changes of pork and chicken are 0.1143 and 0.0183 , indicating substitution. For illustration, only the own-price and income elasticities and the errors of simulation over the sample period as measures of fit are presented in table 3. 
In the table, most own-price elasticities of major food categories in such food groups as meat and other animal proteins, fresh fruits, fresh vegetables, and processed fruits and vegetables have statistically significant estimates with an expected negative sign. The estimates for rice and fresh and frozen fish, however, are positive but not statistically significant. This poor estimate for fish is partly because of difficulty in defining prices and quantities for such a wide variety of fish species, and partly because large amounts of fish are consumed away from home and influenced by menu prices instead of the price of raw fish. Regarding the income elasticities, the statistically significant estimates are for beef, pork, eggs, cheese, evaporated and dry milk, salad and cooking oils, tomatoes, celery, canned tomatoes, and coffee. Although some income elasticity estimates for such foods as turkey are negative, this may not imply that the goods are inferior, because the estimates are not statistically significant. The simulation performance based on the calculated relative root-mean-square errors to sample means in the last column of the table indicates that the errors of simulated quantities demanded are less than $5 \%$ in most cases. The close correspondence between simulated values and sample observations indicates that this demand system is reliable for use in estimating nutrient elasticities.

Using the demand elasticities reported in Huang and the food shares of nutrients contained in table 2, nutrient elasticities on the basis of equation (6) are calculated. A set of nutrient elasticities, showing the effects on fifteen nutrients in response to changes in thirty-five food prices, and per capita income, are computed and reported in table 4 . For example, a $1 \%$ increase in the price of beef (holding other prices and income the same) will affect the amount of all food consumption through the interdependent demand relationships. These changes in food consumption will reduce per capita food energy by $0.027 \%$, protein by $0.091 \%$, and fat by $0.025 \%$, but vitamin A will increase by $0.064 \%$. Although beef contains no vitamin $A$, its nutrient elasticity is influenced by cross-commodity effects, where the crossprice elasticities of carrot and chicken (both rich in vitamin A) in response to changing beef prices are positive. Among other nutrient elasticities in the table, a marginal $1 \%$ increase in the price of eggs may cause cholesterol to decrease by $0.031 \%$. The same price change for carrots may cause vitamin A to decrease by
$0.11 \%$, while for oranges the price change may cause vitamin $\mathrm{C}$ to decrease by $0.194 \%$. Finally, more nutrients are available with an increase in per capita income. The nutrient income elasticities are estimated in the range of 0.138 to 0.388 (last column in table 4 ).

All fifteen nutrients studied are consumed in decreasing or increasing amounts when food prices change, depending on how price changes manifest themselves through own- and crossprice elasticities. On the other hand, nutrient income elasticities reflect the combined effect of all income elasticities in the food demand system. These nutrient elasticities, which represent a total consumer nutrient profile, are useful in developing a model for studying food program effects on the quality of consumer diets. One way to accomplish this task is to simulate alternative food policy scenarios and explore the effects of food prices and income changes on nutrient availability of consumers.

For example, one may use nutrient income elasticities to evaluate the effects of income changes on consumer dietary quality. This is especially useful for monitoring the segment of the population whose incomes fall below the poverty level. Some government food assistance programs, such as the Food Stamp Program, increase the food purchasing power of low-income households by issuing monthly allotments of coupons to eligible households that can only be used to purchase food. Food policy decision makers, therefore, can use the information of nutrient income elasticities to assess the Food Stamp Program effects on the amount of nutrients welfare recipients receive.

\section{Conclusion}

Americans seem increasingly concerned about their nutritional and health status. A better understanding of the economic forces that influence consumer food choice, and thus nutrient availability, is important to food policy decision makers. Food demand analysts need to broaden their theoretical and methodological base of research and provide timely information about the effects of economic factors on the nutritional status of consumers.

This study explores the linkage of the determinants of food choice with consumer nutrient availability by developing a procedure to measure changes in nutrient availability as the demand for food items changes. It uses demand elasticities from traditional demand analysis to 


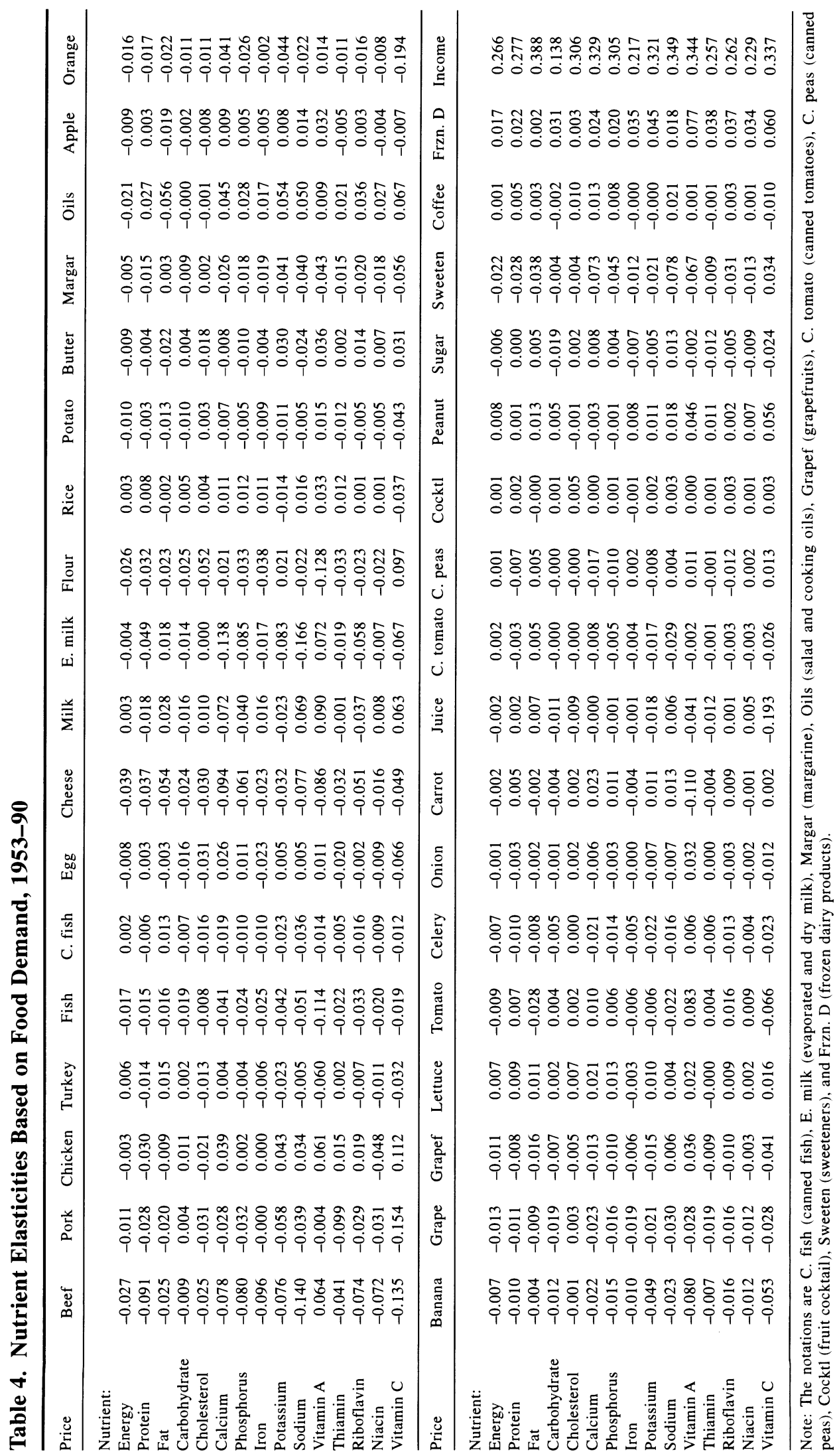


estimate elasticities of changes in the nutritional content of consumer diets. The unique feature of the procedure is that existing interdependent demand relationships can be incorporated into measuring the changes in nutrients available to consumers. The procedure was applied to estimating nutrient elasticities for fifteen nutrients in response to changes in thirtyfive food prices and per capita income. These nutrient elasticities, when viewed as a total consumer nutrient profile, provide useful information for food policy decision makers to assess the food program effects on the quality of consumer diets.

To develop a comprehensive food demand and nutrition study, some further collaborative research between economists and nutritionists is needed. One problem encountered in this study is the difficulty in obtaining accurate nutrient information corresponding to food disappearance data commonly used by demand analysts. The disappearance data is normally compiled as the residual of the food commodity supply-utilization table to reflect disappearance of food into the marketing system. Most available nutrition information, however, gives detailed nutritive values of the amount of edible portion of food products but not of disappearance quantities. To justify the use of these nutritive values, a fixed proportion between the amount of edible portion of a particular food and its disappearance quantity has to be assumed. Accordingly, the relative changes in quantities, and thus the measured nutrient elasticities generated from either edible portion data or disappearance data, should be the same. In addition, the use of disappearance data hardly can distinguish nutritive values from different food preparation methods. For example, chicken fried in animal fat or vegetable oils has far different properties from those of roasted chicken.

[Received July 1994; final revision received September 1995.]

\section{References}

Adrian J., and R. Daniel. "Impact of Socioeconomic Factors on Consumption of Selected Food Nutrients in the United States." Amer. J. Agr. Econ. 58(February 1976):31-38.

Basiotis, P., M. Brown, S.R. Johnson, and K.J. Morgan. "Nutrient Availability, Food Costs, and
Food Stamps.” Amer. J. Agr. Econ. 65(November 1983):685-93.

Brown, D.J., and L.F. Schrader. "Cholesterol Information and Shell Egg Consumption." Amer. J. Agr. Econ. 72(August 1990):548-55.

Capps, O., Jr., and J. Schmitz. "A Recognition of Health and Nutrition Factors in Food Demand Analysis." W. J. Agr. Econ. 16(July 1991):21-35.

Devaney B., and T. Fraker. "The Dietary Impacts of the School Breakfast Program." Amer. J. Agr. Econ. 71(November 1989):932-48.

Gebhardt, S.E., and R.H. Matthews. Nutritive Value of Foods. Washington DC: U.S. Department of Agriculture, Human Nutrition Information Service, Home and Garden Bulletin No. 72, June 1991.

Gould, B.W., T.L. Cox, and F. Perali. "Demand for Food Fats and Oils: The Role of Demographic Variables and Government Donations." Amer. J. Agr. Econ. 73(February 1991):212-21.

Huang, K.S. A Complete System of U.S. Demand for Food. Washington DC: U.S. Department of Agriculture, ERS Technical Bulletin No. 1821, September 1993.

Lancaster, K.J. "A New Approach to Consumer Theory." J. Polit. Econ. 74(February 1966):132-57.

Pitt, M.M. "Food Preferences and Nutrition in Rural Bangladesh." Rev. Econ. and Statist. 65(February 1983):105-14.

Putnam, J.J., and J.E. Allshouse. Food Consumption, Prices, and Expenditures, 1970-90. Washington DC: U.S. Department of Agriculture, ERS SB840, August 1992.

Sahn, D.E. "The Effect of Price and Income Changes on Food-Energy Intake in Sri Lanka." Econ. Develop. and Cultur. Change 63(January 1988):315-40.

Senauer, B., E. Asp, and J. Kinsey. Food Trends and the Changing Consumer. St. Paul MN: Eagan Press, 1991.

U.S. Department of Agriculture, Human Nutrition Information Service. Washington DC: Composition of Foods: Poultry Products, Agr. Handbook No. 8-5, 1979; Composition of Foods: Pork Products, Agr. Handbook No. 8-10, 1992; and Composition of Foods: Beef Products, Agr. Handbook No. 8-13, 1990.

U.S. Department of Agriculture, Human Nutrition Information Service. The Food Guide Pyramid. Home and Garden Bulletin, No. 252, Washington DC, August 1992.

U.S. Department of Commerce. Survey of Current Business. Various issues.

U.S. Department of Labor. CPI Detailed Report. Various issues. 